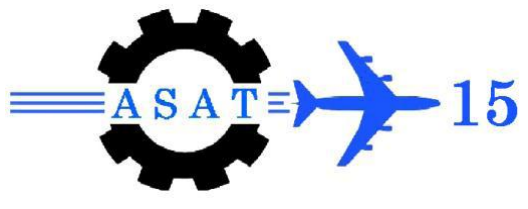

\title{
Damping Properties of Nano-Hybrid GFRE Composites
}

\author{
$\left\{\text { U. A. Khashaba }{ }^{*} \text { K. A. Alnefaie, S.M. Aldousari }\right\}^{\dagger}$
}

\begin{abstract}
This research aims to perform a symmetric investigation regarding the multiwall carbon nanotube (MWCNT) effect on the damping properties of different composite configurations. Nanophased epoxy is ultrasonically prepared and used to fabricate MWCNT/E nanocomposite as well as to hybridize advanced composite laminates with different fiber configuration. The hybridized composite laminates include, quasi-isotropic $[0 / \pm 45 / 90]_{\text {s }}$ glass fiber reinforced nanophased-epoxy (QI-GFR/MWCNT/E) and unidirectional $[0]_{8}$ glass fiber reinforced nanophased-epoxy (UD-GFR/MWCNT/E). Free vibration tests are used for characterization the damping properties through the exponential decay response of the tested materials, while the frequency response function (FRF) is used for determination the storage and loss moduli. The storage moduli (flexural moduli) and loss moduli of the investigated materials were determined using free vibration tests as a nondestructive technique. The storage modulus of MWCNT/E nanocomposite was improved by $7.3 \%$ while the storage moduli of QI-GFR/MWCNT/E and UI-GFR/MWCNT/E are reduced by $9.1 \%$ and $5.2 \%$ respectively. The experimental investigations reveal that the addition of $1 \mathrm{wt} \%$ MWCNTs improves the damping ratio of the newly prepared materials in some cases to about $100 \%$.
\end{abstract}

Keywords: Ultrasonic dispersion, epoxy, nanocomposites, nano-hybrid composite laminates, free vibration, storage and loss moduli, nondestructive test.

\section{Introduction}

Epoxy resins have been extensively investigated because of their superior mechanical properties, excellent dimensional stability, outstanding adhesion and coating properties, and good corrosion resistance [1]. Epoxies have a wide range of applications, including fiberreinforced composite laminates, general purpose adhesives, coatings, flooring, and caulking. Recently, significant effort has focused on further improving of epoxy materials using nanofillers such as $\mathrm{TiO}_{2}$ [2], $\mathrm{SiC}$ [3], Silver [4], $\mathrm{SiO}_{2}$ [5,6], $\mathrm{Al}_{2} \mathrm{O}_{3}$ [7-10], carbon nanotubes (CNTs) [9-19].

Among these nanofillers, carbon nanotubes (CNTs) have taken a prominent position for a new generation of high-performance nanocomposites because of their novel structure and several remarkable mechanical, thermal, and electrical properties [20]. Carbon nanotubes are known to have an elastic modulus of up to $1 \mathrm{TPa}$ and predicted tensile strengths of the order of 100 GPa. In combination with these properties, CNTs also have the unusual attributes of low density for lightweight structures $[9,12]$. Because of their ultra-small, nanometer scale size

khashabu@hotmail.com

$\dagger$ Department of Mechanical Engineering, Faculty of Engineering, King Abdulaziz University, P.O. Box 80204, Jeddah 21589, Saudi Arabia. 
and low density, the surface area to mass ratio (specific area) of carbon nanotubes is extremely large. Therefore, in a nanotube-based polymeric composite structure, it is anticipated that high damping can be achieved by taking advantage of the interfacial friction between the nanotubes and the polymer resins [21]. The large aspect ratio and high elastic modulus features of CNTs result in composites with large differences in strain between the constituents, which could further enhance the interfacial energy dissipation ability. Accordingly, carbon nanotube-based composite is becoming increasingly popular and offers great potential for highly demanding damping applications such as aerospace structures, precision engineering, micro-positioning and control.

The outstanding properties of the carbon nanotubes make them promising filler material to improve mechanical, thermal and electrical properties of polymers. The key point is to transfer the potential properties of CNTs to the polymer composites. Due to the high-surface energy of nanotubes they have a tendency to aggregate together owing to the strong attractive forces between the CNTs themselves. The van der Waals attractive interactions owing to high aspect ratio of MWCNTs are another reason for the agglomeration of CNTs in epoxy resins [10,13,16,22-27]. The aggregated CNTs are in the form of bundles or ropes [25], usually with highly entangled network structure that is very difficult to disperse them. Therefore, the homogeneous dispersion of nanofillers within the polymer matrix is a prerequisite of any composites and presents a problem to be solved for nanotube-reinforced epoxy. Different techniques have been used to enhance the dispersion of nanoparticles in polymer resins, includes the use of melt mixing [23], mechanical shear mixer [28], sol-gel (modification the chemical surface of fillers) [7], in-situ polymerization [23], three-roll mill [13,15], Ball milling [12] and mechanical stirring [29]. According to previous researchers [6-19], ultrasonic agitation method is more effective to disperse CNTs into epoxy resins. Therefore, in the present work high power ultrasonic liquid processor will be used to disperse MWCNTs in epoxy resin.

In sonication process, the sonicator probe generates high-intensity ultrasound waves that launched into the liquid particle-matrix-mixture, where cavitation bubbles can develop and grow during several cycles until they attain a critical diameter, which induces their implosion. This collapse causes locally extreme conditions as a very high local pressure and very high temperatures, a so called hot-spot. Due to these hot-spots a splitting up of particle agglomerates can occur. The shock waves from the implosive bubble collapse in combination with micro-streaming generated by cavitation oscillations lead to dispersion effects $[2,3,7,30]$. If a mixture containing a gas like air more bubbles are likely to form during sonication, which can lead to a better dispersion. On the other hand the entrapped air impairs the flow ability of the mixture. Thus, a positive effect superposes a negative effect [2]. Sonication parameters can play an important role in enhancement the dispersion of nanoparticles in viscous polymers. These parameters includes: sonication power, frequency, amplitude, time, temperature, energy, energy densities, dimension of sonicator probe, immersion depth of the sonicator probe, and sonication mode (pulsed or contentious). Many research efforts are needed to specify all the sonication parameters, which are very important for the researchers in this specific area. Therefore, the mentioned sonication parameters are quantitatively described in the current research work.

The epoxy monomers react with curing agent (generally containing amine groups) during its cure to form a three-dimensional cross-linked network with a certain thermomechanical properties. The degree and uniformity of curing reaction will affect considerably the bulk material properties [31]. Various degrees of CNT concentrations may influence curing reactions to a different degree or sometimes with opposite effect [32]. Zhou et al. [33] showed 
that both unfunctionalized and functionalized multi-walled carbon nanotubes (MWCNTs) have an accelerating influence on the reaction kinetics. They also found that the degree of epoxy cure is decreased by the addition of $1 \mathrm{wt} \%$ unfunctionlized MWCNTs. This result was evidenced by the lower value of the glass transition temperature $\left(T_{g}\right)$ of the cured nanocomposite by $15^{\circ} \mathrm{C}$ compared to the neat epoxy. Tao et al. [1] also observed that with only $1 \mathrm{wt} \%$ of carbon nanotubes, the $T_{g}$ of epoxy composites was lowered by $10-30{ }^{\circ} \mathrm{C}$ approximately. As discussed above, the effects of CNTs on the curing reaction can lead to significant thermal and mechanical property changes of epoxy/CNT nanocomposites, which would complicate their property evaluation. This issue has attracted more and more attention recently, but only limited progress has been made. This is likely due to the difficulty in the quantitative assessment of the above effect [32].

The damping of an engineering structure is important in many aspects of noise, vibration control, and fatigue endurance, since it controls the amplitude of resonant vibration response [34]. A viscoelastic material is characterized by having both viscous and elastic behavior [35]. A purely elastic material stores all the energy upon loading, and returns an equal amount of energy when the load is removed. The result is the stress and strain are in phase during the cyclic loading and unloading process. Hooke's Law applies for elastic materials where the stress is proportional to strain, and the modulus is the ratio of stress to strain. In contrast, the purely viscous material does not return any of the energy stored during loading, and the energy is lost once the load is removed. The viscoelastic material returns some of the stored energy when the load is removed, and the portion that is not returned is dissipated in the form of heat. The cyclic stress due to the loading frequency is out of phase with the strain by some angle $\delta$, which is a measure of the damping, Fig.1.

The primary mechanisms that have been suggested to contribute to damping in composites includes [36-38]: viscoelastic response of the constituents, friction and slipping at the fibermatrix interface, thermoelastic damping due to cyclic heat flow, and damage initiation and growth. Excluding the contribution from any cracks and other defects, the internal damping of a composite is determined by the following variables: properties and relative proportions of the matrix and the reinforcement, dimensions of the inclusions, orientation of the reinforcement with respect to the loading axis, and surface treatments of the reinforcement and void content.

Botelho et al. [36] studied the effect of stacking sequences on the elastic modulus and damping properties of CFR/epoxy laminates. They computed the damping properties based on the measured exponential decay rate of the free vibration response. Their results showed that the calculated elastic modulus for $[0 / 0]_{\mathrm{s}},[0 / 90]_{\mathrm{s}}$, and $[ \pm 45]_{\mathrm{s}}$ composites, using composite micromechanics, were respectively, $17.2 \%, 21.5 \%$, and $5.0 \%$ higher than the experimental result. This behavior because the micromechanics approach assumes ideal bonding between fiber/matrix interface, perfect alignment of fibers and absence of voids, which cannot be avoided during fabrication of the composite laminate. The loss factor $(\tan \delta)$ of $[0 / 0]_{\mathrm{s}},[0 / 90]_{\mathrm{s}}$, and $[ \pm 45]_{\mathrm{s}}$ laminates were $0.0133,0.0129$, and 0.0245 respectively. These values are not presented in their work but can be easily calculated from the exponential decay response of the tested materials. These results indicate that the loss factor of $[0 / 90]_{\mathrm{s}}$, is lower than that for $[ \pm 45]_{\mathrm{s}}$ laminate. On the other hand, for CFR/polyamide composite laminates, Botelho et al. [39] reported that the loss factors of $[0 / 90]_{\mathrm{s}}$, and $[ \pm 45]_{\mathrm{s}}$ stacking sequence were 0.016 , and 0.014 respectively. The contrast results of loss factor for CFR/Epoxy and CFR/polyamide composites were due to the effect of the matrix type. 


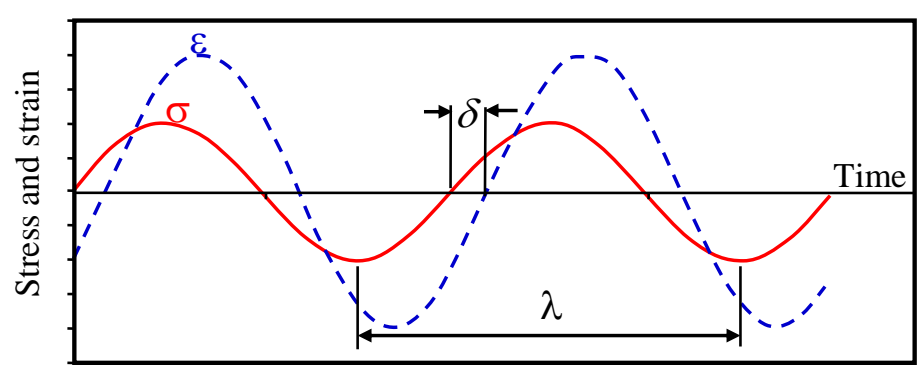

Fig.1. Stress and strain vs. time of a viscoelastic material

Montazeri [40] studied the viscoelastic and mechanical properties of multi-walled carbon nanotube (MWNT)/epoxy composites with different weight fractions $(0.1 \%, 0.5 \%, 1 \%$ and 2 wt $\%$ ) by performing tensile and dynamic mechanical thermal analysis (DMTA) tests. The MWNT/epoxy nanocomposites were fabricated by sonication and a cast molding process. The results showed that the tensile strength and modulus for $2 \mathrm{wt} \%$ MWNT increased by $17 \%$ and $23 \%$ respectively. Compared to neat epoxy, the dynamic mechanical results indicated a $46 \%$ improvement in storage modulus for $0.5 \mathrm{wt} \% \mathrm{MWNT} / \mathrm{epoxy}$ at room temperature. Due to the lower cross-link densities in the nanocomposites, the glass transition temperature decreased with higher MWNT contents. Venkatanarayanan and Stanley [41] reported that the additions of MWCNTs in three different proportions by weight $(0.1 \%, 0.5 \%$ and $1.0 \%)$ of hybrid resin (a blend of $60 \%$ epoxy and $40 \%$ polyester) improve the damping efficiency of the laminates and also control the damages to the laminates. Mantena et al. [42] observed that in nondestructive vibration response the dynamic modulus was increased and the damping was marginal dropped with the addition of multi-wall carbon nanotubes to nylon-6/pristine.

Many investigators $[1,9,11,18,22,43-47]$ reported that dispersing $1 \mathrm{wt} \%$ of CNTs leads to significant improvement in the mechanical properties. Therefore, the aim of the present work is to investigate the effect of $1 \mathrm{wt} \%$ MWCNTs on the mechanical and damping properties of nanophased epoxy (Araldite PY 1092-1) and different hybrid multi-scale composite laminates. The latter composite laminates includes: quasi-isotropic angle-ply [0/ $\pm 45 / 90]_{\mathrm{s}}$ glass fiber reinforced epoxy composite laminates, and unidirectional glass fiber reinforced epoxy composite laminates. The dispersion of $1 \mathrm{wt} \%$ MWCNT in epoxy resin is carried out using high intensity ultrasonic liquid processor. The composite laminates (with and without MWCNT) are locally fabricated using hand lay-up technique. Special roller is applied with moderate pressure for remove any visible air bubbles, provides fast impregnation and good wetting of glass fibers with wetting fiber and de-agglomerations of MWCNTs in composite laminates. The storage moduli (flexural moduli), loss moduli, loss factors, and damping ratios are determined experimentally for the investigated materials using the exponential decay response of flexural (cantilever) specimen using modal testing technique.

\section{Experimental Work}

\subsection{Materials}

Six different materials categories are prepared in this work. These materials include: neat epoxy, MWCNT/E nanocomposites, quasi-isotropic angle-ply $[0 / \pm 45 / 90]_{\mathrm{s}}$ glass fiber reinforced epoxy composite laminate (QI-GFR/E), unidirectional glass fiber reinforced epoxy composite laminate (UD-GFR/E), and GFR/MWCNT/E and UD-GFR/MWCNT/E hybrid multi-scale composite laminates. Fig. 2 is a schematic representation of the hybrid multi-scale composite materials that have been developed. The selected percent of MWCNT is $1 \mathrm{wt} \%$, 
which showed improvement in the mechanical properties by many investigators $[1,9,11,18,22,43-47]$. Details about the constituent materials that used in this work are presented in Table 1.

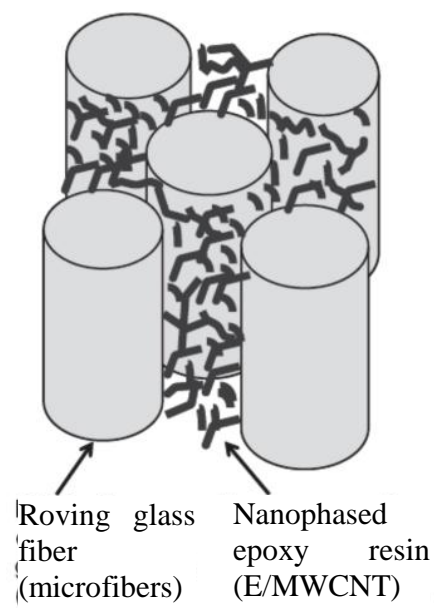

Fig. 2. Schematic representation of hybrid multi-scale composite materials.

Table 1. Constituents of the investigated materials

\begin{tabular}{|c|c|}
\hline Test materials & Constituent materials \\
\hline Neat epoxy & $\begin{array}{l}\text { Epoxy part A (Resin): Araldite PY } 1092-1 \\
\text { (100 part by weight) } \\
\text { Epoxy part B (Hardener): HY } 1092 \text { ( } 45 \text { part } \\
\text { by weight) } \\
\text { Viscosity of epoxy (A and B) equal } 300 \mathrm{cps} \text { at } \\
25^{\circ} \mathrm{C} \text {. }\end{array}$ \\
\hline $\begin{array}{l}\text { Epoxy/ Multi-Wall Carbon Nanotube (MWCNT/E) } \\
\text { nanocomposites }\end{array}$ & $\begin{array}{l}\text { Epoxy } \\
\text { Multi-Wall Carbon Nanotube: } 1 \mathrm{wt} \% \text { (epoxy } \\
\text { parts A+B) } \\
\text { ○ Outer diameter }<8 \mathrm{~nm} \\
\circ \text { Length } 10-30 \mu \mathrm{m} \\
\circ \text { Purity }>95 \mathrm{wt} \%\end{array}$ \\
\hline $\begin{array}{l}\text { Quasi-isotropic angle-ply }[0 / \pm 45 / 90]_{\mathrm{s}} \text { glass fiber } \\
\text { reinforced epoxy (QI-GFR/E) composite laminates }\end{array}$ & $\begin{array}{l}\text { Epoxy } \\
\text { E-roving glass-fiber linear density = } 1.2 \mathrm{~g} / \mathrm{m} \text {. }\end{array}$ \\
\hline $\begin{array}{l}\text { Quasi-isotropic angle-ply }[0 / \pm 45 / 90]_{\mathrm{s}} \text { glass fiber } \\
\text { reinforced MWCNT/E composite laminates (QI- } \\
\text { GFR/MECNT/E) }\end{array}$ & $\begin{array}{l}\text { Epoxy } \\
\text { E-roving glass-fiber linear density }=1.2 \mathrm{~g} / \mathrm{m} \text {. } \\
\text { Multi-Wall Carbon Nanotubes: } 1 \text { wt } \% \text { (epoxy } \\
\text { parts A+B) }\end{array}$ \\
\hline $\begin{array}{l}\text { Unidirectional glass fiber reinforced epoxy (UD- } \\
\text { GFR/E) composite laminates }\end{array}$ & $\begin{array}{l}\text { Epoxy } \\
\text { E-roving glass-fiber linear density }=1.2 \mathrm{~g} / \mathrm{m} \text {. }\end{array}$ \\
\hline $\begin{array}{l}\text { Unidirectional Glass fiber reinforced MWCNT/E } \\
\text { composite laminates (UD-GFR/MWCNT/E) }\end{array}$ & $\begin{array}{l}\text { Epoxy } \\
\text { E-roving glass-fiber linear density }=1.2 \mathrm{~g} / \mathrm{m} \text {. } \\
\text { Multi-Wall Carbon Nanotubes: } 1 \text { wt } \% \text { (epoxy } \\
\text { parts A+B) }\end{array}$ \\
\hline
\end{tabular}




\subsubsection{Preparation of neat epoxy panel}

Epoxy part A (100 part by weight) was mixed with epoxy part B (45 part by weight) and stirred manually for 10 min [11]. The hardener (epoxy part B) was added gradually (i.e. drop by drop) while the mixture was being stirred. After stirring the epoxy resin was poured into glass mold $(300 \times 300 \mathrm{~mm})$ that treated by release agent (liquid wax). The mold then procured in an oven for $4 \mathrm{~h}$ at a temperature of $40{ }^{\circ} \mathrm{C}$ and post cured by ramping the temperature from $40{ }^{\circ} \mathrm{C}$ to $80{ }^{\circ} \mathrm{C}$ and hold for $2 \mathrm{~h}[28]$.

\subsubsection{Preparation of MWCNT/E nanocomposites}

In the present work $1 \mathrm{wt} \%$ of MWCNTs was dispersed in epoxy resin using a high intensity ultrasonic liquid processor, Cole-Parmer, Inc., USA. The dispersion of MWCNTs is more difficult in a viscous medium, where the viscosity of polymer increased sharply as the CNTs loading increased [7]. Due to the fact that sonication parameters can play an important role in enhancement the dispersion of CNTs in viscous polymers and accordingly the mechanical properties of the nanocomposites, the following sonication parameters are carefully selected based on the literature review to disperse MWCNTs in epoxy part A:

- To overcome the temperature raise during sonication process a cylindrical aluminum containers with flat bottom and small diameter $(80 \mathrm{~mm})$ is immersed in ice cooling bath to a level roughly equal to that of the internal mixture. The high thermal conductivities of the aluminum will maximize the dissipation of heat by the water/ice cooling bath. The small diameter of the container will maximize the surface area of the mixture that subjected to the water/ice cooling bath and consequently the dissipation of heat by the cooling bath. In addition, the small diameter of the container will maximize the mixtureprobe surface area exposed to the acoustic waves.

- Sonicator probe with $25 \mathrm{~mm}$ diameter was fixed for all the sonication processes [7]. Probes with larger tip diameters produce less intensity, but the energy is released over a greater area. The larger the tip diameter, the larger the volume that can be processed, but at lower intensity.

- Immersion depth of the sonicator probe was fixed at $50 \mathrm{~mm}$, at the center of the container (to avoid the contact between the probe and the container walls), and away about $20 \mathrm{~mm}$ from the bottom of the container. Probe immersion depths between $(20$ to $50 \mathrm{~mm})$ are recommended to prevent the nebulization (formation and release of aerosols) owing to rise of agitation surface [48].

- The maximum sonication temperature not exceeds $70^{\circ} \mathrm{C}$ [49]. For this purpose, temperature probe tip was fixed at about $1 \mathrm{~cm}$ away from the sonicator probe [48].

- Another important parameter for the ultrasonic dispersion is the sonication amplitude, which is correlated to the power input into the mixture. The maximum sonication amplitude $(100 \%)$ was applied during the sonication processes. It has been addressed that the best dispersion results are obtained at the highest amplitude of $100 \%$, and hence the highest power input [2,5].

- Constant sonication energy $(2700 \mathrm{~kW} . \mathrm{s})$. The increased viscosity of the epoxy resin due to mixing MWCNTs can dampen the cavitation process. Therefore maximum power was used $(750 \mathrm{~W})$ [2,5] for $60 \mathrm{~min}[10]$.

- Constant energy densities $(7714 \mathrm{~W} \cdot \mathrm{s} / \mathrm{ml})$. All the sonication processes were implemented at constant energy densities using constant mixture volume $350 \mathrm{ml}$. Bittmann et al. [2] 
reported that the time needed to achieve a good dispersion of $\mathrm{TiO}_{2}$ nanoparticles/epoxy is approximately proportional to the mixture volumes.

- Operating in pulsed mode with $15 \mathrm{~s}$ on and $30 \mathrm{~s}$ off. Sonication in pulsed mode retards the rate of temperature increase in the mixture, minimizing unwanted side effects and allowing better temperature control than continuous mode operation. Pulse mode operation with long off periods will help avoid foaming in samples [48]. Uddin and Sun [7] applied $15 \mathrm{~s}$ on and $15 \mathrm{~s}$ off, while Chen et al. [5] applied $12 \mathrm{~s}$ on and $48 \mathrm{~s}$ off. On the other hand Zhou et al. [19] applied $50 \mathrm{~s}$ on and $25 \mathrm{~s}$ off.

After sonication, the hardener was added to the epoxy resin and manually stirred for $10 \mathrm{~min}$ [11]. The nanophased epoxy now is ready to pour into the mold and/or to hybridize the advanced composites laminates (GFR/MWCNT/E) composite laminates. For MWCNT/E nanocomposites, the panels were prepared and cured by following the same manufacturing procedure of neat epoxy panel.

\subsubsection{Fabrication of hybrid multi-scale GFR/MWCNT/E composite laminates}

Two types of hybrid multi-scale GFR/MWCNT/E composite laminates are fabricated using hand lay-up technique that developed for fabricating unidirectional and angle ply composite laminates by Khashaba [50] and applied in many publications [51-56]. The first type is the QI-GFR/MWCNT/E laminate and the second type is UD-GFR/MWCNT/E laminate.

\section{(a) Fabrication of QI-GFR/MWCNT/E composite laminates}

- Eight templates were used to lay-up the fiber bundles in $0^{\circ},+45^{\circ}-45^{\circ}, 90^{\circ}, 90^{\circ}$,$45^{\circ},+45^{\circ}$, and $0^{\circ}$ directions. The parallel bundles of fibers were fixed on the frame of the templates. The normal distance between the adjacent bundles was five $\mathrm{mm}$.

- The upper surface of the mold is glass plate $(600 \times 400 \mathrm{~mm})$ treated by release agent (liquid wax).

- The first layer of the nanophased epoxy resin was spread on the glass plate.

- The first template with glass fiber in $0^{\circ}$ direction was placed on the nanophased epoxy and consolidated using aluminum roller with longitudinally narrow slots parallel to its axis and perpendicular to the fiber directions. This type of rollers removed any visible air bubbles that escaped into the slots and provides fast impregnation and good wetting of glass fibers with the nanophased matrix. In additions, applying rolling with moderate pressure can play an important role in de-agglomeration of the MWCNTs owing to the strong attractive forces between the CNTs themselves and the van der Waals attractive interactions arise from the high aspect ratio of MWCNTs. Therefore, the resultant laminate has good fiber-matrix interfacial bond strength.

- Rolling is continued until the lamina is fully impregnated and all visible air inclusions are removed. This procedure was repeated with alternative layers of nanophased epoxy and the next glass fiber layers, which are in the following sequence: $+45^{\circ},-45^{\circ}$, $90^{\circ}, 90^{\circ},-45^{\circ},+45^{\circ}$, and $0^{\circ}$.

- The last layer (nanophased epoxy) was covered by a cellophane paper that wounded on a smooth round aluminum pipe and rolled to remove any visible air bubbles and squeeze the excess resin.

- To obtain smooth upper surface with nearly constant thickness a glass plate was placed on the cellophane paper and a weight of $30 \mathrm{~kg}$ was distributed on the glass plate, BS 3496. 
- The laminate was precured under uniform pressure for $24 \mathrm{~h}$ at room temperature, ISO 1268 , and post cured at room temperature for further 21 days.

- The margins of the laminate, up to at least $20 \mathrm{~mm}$ from the edge, were cut and the working portion of the specimens was taken away from the edge by about $30 \mathrm{~mm}$.

The quasi-isotropic $[0 / \pm 45 / 90]_{\mathrm{s}}$ angle-ply glass fiber reinforced epoxy composite laminate (QI-GFR/E) was manufactured by the same procedure using neat epoxy resin instead of nanophased epoxy resin.

\section{(b) Fabrication of UD-GFR/MWCNT/E composite laminates}

The unidirectional composite laminate UD-GFR/E and UD-GFR/MWCNT/E composite laminates were fabricated by following the same manufacturing procedure of QI-GFR/E and QI-GFR/MWCNT/E respectively using eight layers of unidirectional glass fiber $\left[0^{\circ}\right]_{8}$.

The fiber volume fractions $\left(V_{f}\right)$ of the manufactured laminates are determined experimentally using the ignition technique according to ASTMD3171. The average value of $V_{f}$ is $33.7 \%$. The variation of $V_{f}$ in any laminate not exceeds $\pm 0.1 \%$ while, the variation of $V_{f}$ among the fabricated laminates (QI-GFR/E, QI-GFR/MWCNT/E, UD-GFR/E, and UDGFR/MWCNT/E) was $\pm 0.4 \%$ due to the different fibers configurations in these laminates.

\subsection{Free Vibration Tests}

A nondestructive impulse-frequency response vibration technique was used by many investigators [36-39,42,57-59] to characterize the dynamic flexural/extensional modulus and damping of different composite materials. Experimental setup is illustrated in Fig. 3. One end of the specimen is fixed as cantilever using special fixture that manufactured for this purpose. Accelerometer (B\&K model 4507 B1) is mounted on the free end of the specimen using special mounting (B\&K model UA1475) that bonded to the free end of the cantilever beam. The specimen is excited by impulse hammer (B\&K model 2302-10). The vibration response was measured using pulse analyzer (B\&K model 3560c).

The amplitude decay as a function of time is recorded and shown directly on the PC display that attached to the pulse analyzer. The frequency response function (FRF) obtained from the impact and accelerometer signals are used accompanied with free vibration decay curve for computing the storage and loss moduli, loss factor, and damping ratio. Table 2 shows the actual specimen dimensions (length, width and thickness), inertia, and masses, which used in the calculations of the damping properties of the investigated materials. These dimension are closed to that reported by Botelho et al. [36,39,58,59] and Zhou et al. [22].

Table 2. Dimensions and masses of free vibration test specimens

\begin{tabular}{lccccc}
\hline \hline Test materials & $\begin{array}{c}\text { Mass } \\
(\mathrm{kg})\end{array}$ & $\begin{array}{c}\text { Span } \\
(\mathrm{m})\end{array}$ & $\begin{array}{c}\text { Width } \\
(\mathrm{m})\end{array}$ & $\begin{array}{c}\text { Thickness } \\
(\mathrm{m})\end{array}$ & Inertia $\left(\mathrm{m}^{-4}\right)$ \\
\hline \hline Neat epoxy & 0.012705 & 0.131 & 0.0200 & 0.0044 & $1.420 \times 10^{-10}$ \\
MWCNT/E & 0.014095 & 0.131 & 0.0201 & 0.0047 & $1.739 \times 10^{-10}$ \\
QI-GFR/E & 0.017440 & 0.131 & 0.01995 & 0.0043 & $1.322 \times 10^{-10}$ \\
QI-GFR/MWCNT/E & 0.018504 & 0.131 & 0.0197 & 0.0046 & $1.598 \times 10^{-10}$ \\
UD-GFR/E & 0.016505 & 0.131 & 0.0200 & 0.0042 & $1.067 \times 10^{-10}$ \\
UD-GFR/MWCNT/E & 0.017864 & 0.131 & 0.0200 & 0.0042 & $1.235 \times 10^{-10}$ \\
\hline \hline
\end{tabular}



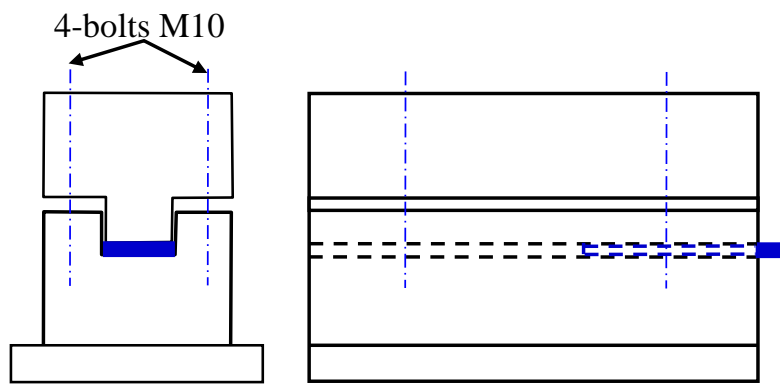

Specimen fixture
Accelerometer

(B\&K model

4507 B1)

mounting (B\&K

model UA1475)

Cantilever beam specimen
Impulse hammer

$(\mathrm{B} \& \mathrm{~K}$

2302-10) moder

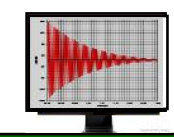

PC

Pulse analyzer

(B\&K model

Fig. 3. Experimental setup of free vibration tests

\section{Theoretical Analysis of Free Vibration}

The viscoelastic response of materials under stress can be modeled as shown in Fig. 4 [36]. The cantilever beam is consider as a discrete system in which the beam is massless and the one third of the whole mass is concentrated at the free end of the beam as shown in Fig 4. Hence, the total mass of the beam at the free end is given as [60]:

$$
m_{b c}=\frac{33}{140} m_{b}
$$

The governing equation of motion for such system will be

$m \ddot{y} t+k y t=0$

where $k$ is the stiffness of the system and $m$ is the total concentrated mass at the free end of the beam. The values of $m$ and $k$ can be estimated from the following equations

$m=\frac{33}{140} m_{b}+m_{t}$

$k=\frac{3 E^{\prime} I}{l^{3}}$

where $m_{t}$ is the mass of the transducer (accelerometer mass, $4.8 \mathrm{~g}+$ accelerometer mounting mass, $0.7 \mathrm{~g}$ ), $E^{\prime}$ is the elastic modulus (storage modulus), $I$ is the moment of inertia of the beam cross-section, and $l$ is the beam length $(131 \mathrm{~mm})$.

The fundamental undamped circular natural frequency $\left(\omega_{n}\right)$ of the system is given as [41]

$\omega_{n}=\sqrt{\frac{k}{m}}=\sqrt{\frac{3 E^{\prime} I}{m l^{3}}}=\frac{\omega_{d}}{\sqrt{1-\zeta^{2}}}=\frac{2 \pi f_{n}}{\sqrt{1-\zeta^{2}}}$

where $\omega_{d}$ is the damped circular natural frequency, $\zeta$ is the damping ratio, and $f_{n}$ is the natural frequency, which determined from the frequency response function (FRF). 


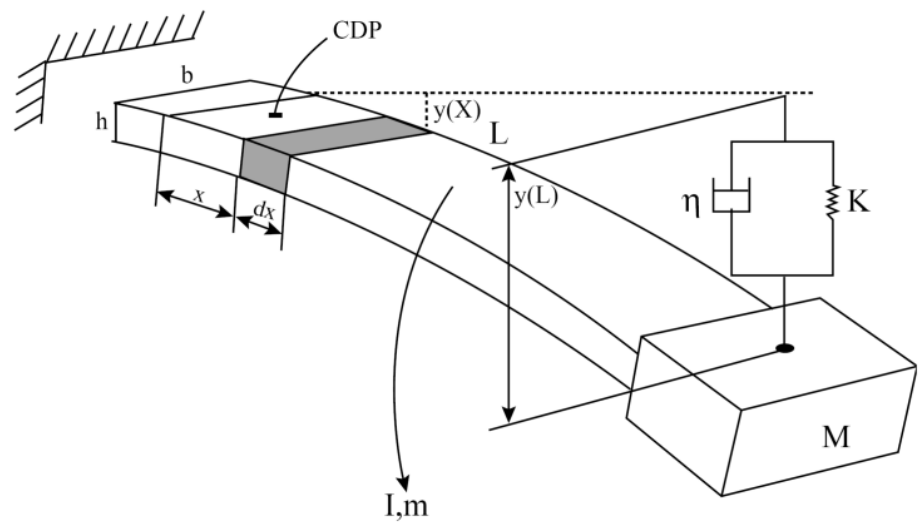

Fig. 4. Voigt-Kelvin model for free vibration analysis [36]. $l$ is the length, $h$ is the thickness, $b$ is the width, $y$ is the deflection of the beam, and $d x$ is the deformation in $x$.

The elastic modulus (storage modulus) can be obtained by substitution of Eq. 3 into Eq. (5) as following

$$
E^{\prime}=\frac{4 \pi^{2} f_{n}^{2} l^{3}}{3 I}\left(m_{t}+\frac{33}{140} m_{b}\right)\left(\frac{1}{1-\zeta^{2}}\right)
$$

The logarithmic decrement, $\Delta$, (the exponential rate of amplitude decay as a function of time) is calculated from the following equation [57].

$$
\Delta=\ln \left(\frac{\delta_{1}}{\delta_{2}}\right)=\frac{1}{n} \ln \left(\frac{\delta_{1}}{\delta_{n}}\right)
$$

where $n$ is the number of peaks; $\delta_{l}$ is the amplitude of the first peak and $\delta_{n}$ is the amplitude after $n$ cycles analyzed in the free vibration decay curve. The damping ratio, $\zeta$, is calculated from the logarithmic decrement, $\Delta$, as following

$$
\zeta=\frac{1}{\sqrt{1+\left(\frac{2 \pi}{\Delta}\right)^{2}}}
$$

Ten tests are implemented for each composite type and the average is used to calculate $\Delta$ and $\zeta$.

Since the stress and strain are out of phase for viscoelastic materials and the dynamic viscoelastic properties are expressed in terms of the complex dynamic Young's modulus $\left(E^{*}\right)$. The real part of the complex quantity (storage modulus, $E^{\prime}$ ) is the elastic behavior of the material associated with the stiffness, and the imaginary component (loss modulus, $E^{\prime \prime}$ ) relates to the material's viscous behavior, and defines the energy dissipative ability. The complex modulus is often presented in the form [35]:

$E^{*}=E^{\prime}+i E^{\prime \prime}$ 
The values of $E^{\prime}$ and $E^{\prime \prime}$ can be estimated from the following equations.

$$
\begin{aligned}
& E^{\prime}=\left|E^{*}\right| \cos (\delta) \\
& E^{\prime \prime}=\left|E^{*}\right| \sin (\delta)
\end{aligned}
$$

The loss factor $(\tan \delta)$ can be determined from the following equation [36-39,57-59]:

$$
\tan \delta=\frac{1}{n \pi} \ln \left(\frac{\delta_{1}}{\delta_{n}}\right)=\frac{E^{\prime}}{E^{\prime \prime}}
$$

Accordingly, $E^{\prime \prime}=E^{\prime} / \tan \delta$

The magnitude of the complex modulus $\left|\mathrm{E}^{*}\right|$ can be estimated from Eq. (10) or (11) as following

$\left|E^{*}\right|=E^{\prime} / \cos \delta=E^{\prime \prime} / \sin \delta$

\section{Results and Discussions}

The frequency response functions (FRF) of the investigated materials are plotted by taking the Fourier transform of the logged time histories as shown in Figs. 5 and 6. From these figures, only the first vibration mode is used in order to calculate the storage and loss moduli, using Eqs. (9) and (16) respectively, due to the fact that it is the predominant wavelet level $[39,59]$. The FRF response is the decomposition of the natural frequencies of a structure or specimen, which corresponds to a typical fingerprint identity of the vibration modes [38]. The number of vibration peak frequencies (vibration modes) and the shape of the FRF response are a direct result of the material damping and the rigidity of the beam under test $[36,38,39]$.

The results in Figs. 5 and 6 showed that the first natural frequency of MWCNT/E nanocomposites, QI-GFR/MWCNT/E laminate and UD-GFR/MWCNT/E laminate are higher than the corresponding materials, which did not include MWCNTs in their composition by about $1.6 \%, 9.0 \%$, and $8.8 \%$ respectively. The increase in natural frequency for the hybrid multi-scale composites (QI-GFR/MWCNT/E, and UD-GFR/MWCNT/E) is approximately by the same level. The natural frequency of MWCNT/E nanocomposites is about five times less than the hybrid multi-scale composites.

Figures 7-9 show samples from free vibration decay curve of the investigated materials. These figures clearly indicate that the decay response of free vibration curves is more pronounced for the tested materials that contains MWCNTs. Figs. 7-9 are used for computing the logarithmic decrement $(\Delta)$ using, Eq. (7). The values of the logarithmic decrement $(\Delta)$ are used for computing damping ratio, Eq. (8), loss factor, Eq. (12) and the storage and loss moduli, Eqs. (6) and (13) respectively. The average computed properties of ten measurements for each material type are illustrated in Table 3. 
Table 3 and Fig.10 show that storage modulus and damping factor of MWCNT/E nanocomposites is improved by $7.3 \%$ and $6.8 \%$ respectively compared to the neat epoxy. The improvement in the damping properties of MWCNT/E nanocomposites can be clearly observed by the rapid decay response of free vibration curve, Fig. $7 \mathrm{~b}$ compared to neat epoxy, Fig. 7a. This behavior was due to the interfacial friction between the nanotubes and the polymer resin, which play an important role for enhancing the damping characteristics of CNTs-based nanocomposites [21,22,45,61,62]. Zhou et al. [22] reported that because of the small size of nanotubes, the surface area to mass ratio (specific area) of carbon nanotube arrays is extremely large. Therefore, in composites with CNT fillers, it is anticipated that high damping can be achieved by taking advantage of the weak bonding and interfacial friction between individual CNTs and resin. Such a debonding mechanism and its effect on the damping characteristics of CNT-filled composites have yet to be explored.

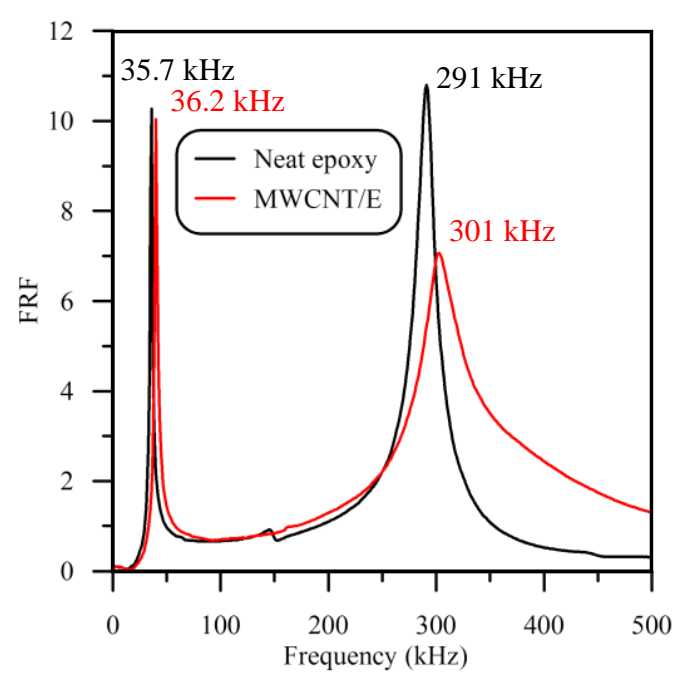

Fig. 5. FRF of neat epoxy and MWCNT-nanocomposites
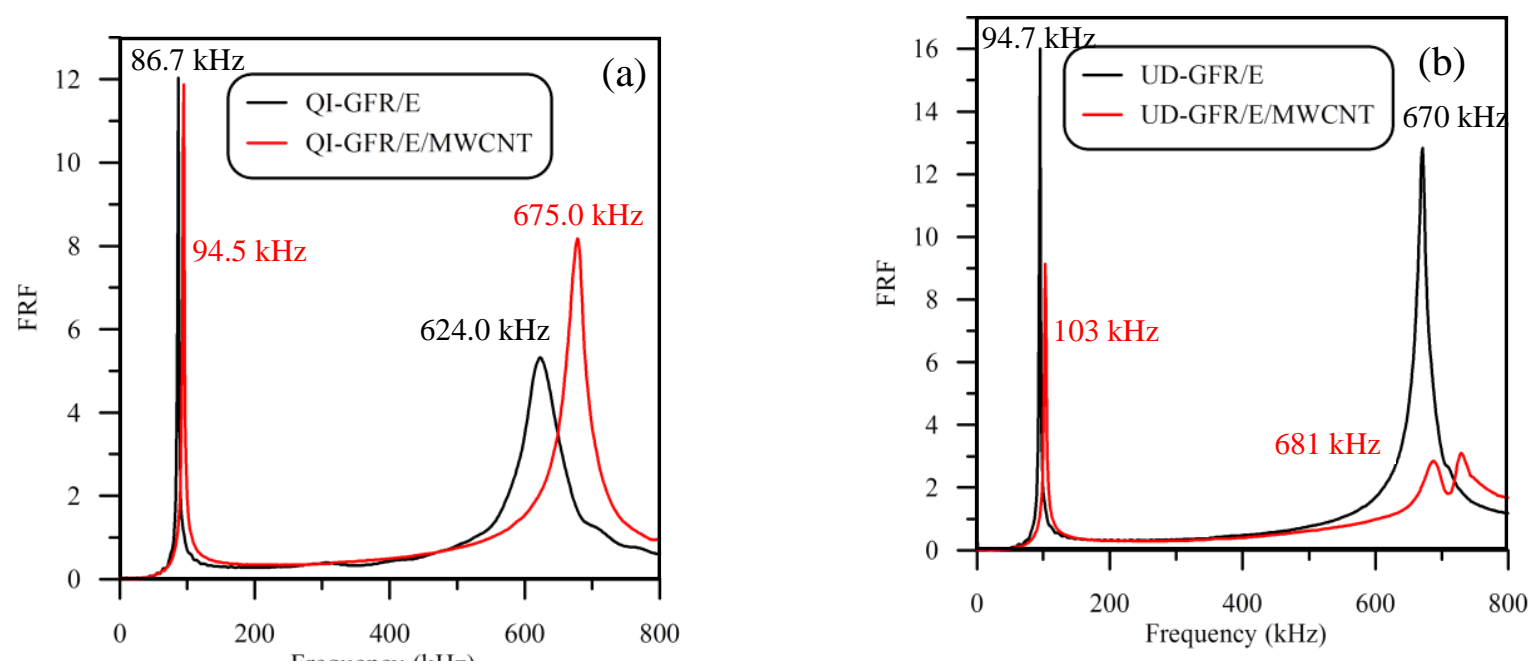

Fig. 6. FRF of (a) QI-GFR/E and QI-GFR/MWCNT/E, and (b) UD-GFR/E and UD-GFR/MWCNT/E. 

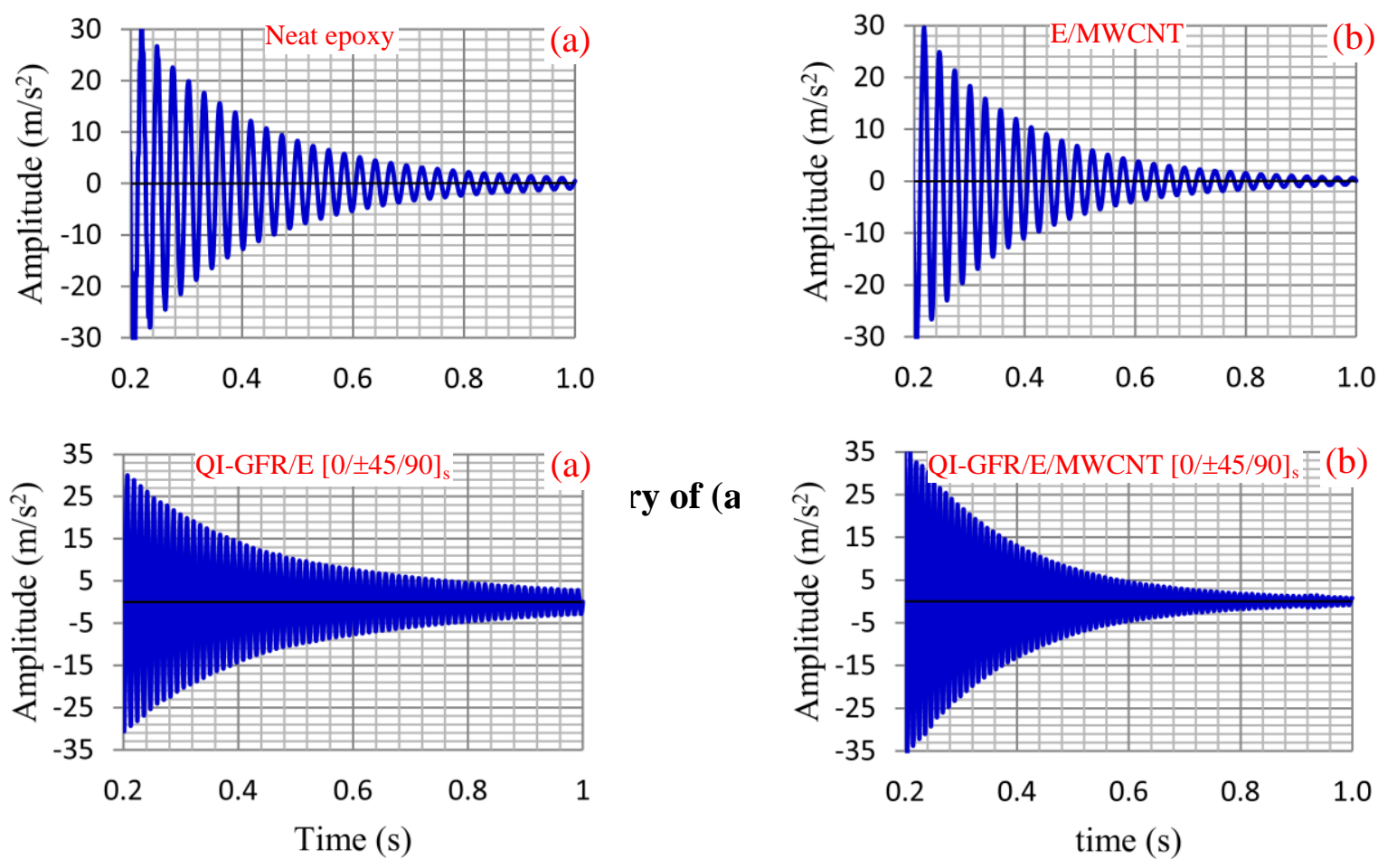

Fig. 8. Vibration amplitude vs. time history of (a) QI-GFR/E, (b) QI-GFR/MWCNT/E.
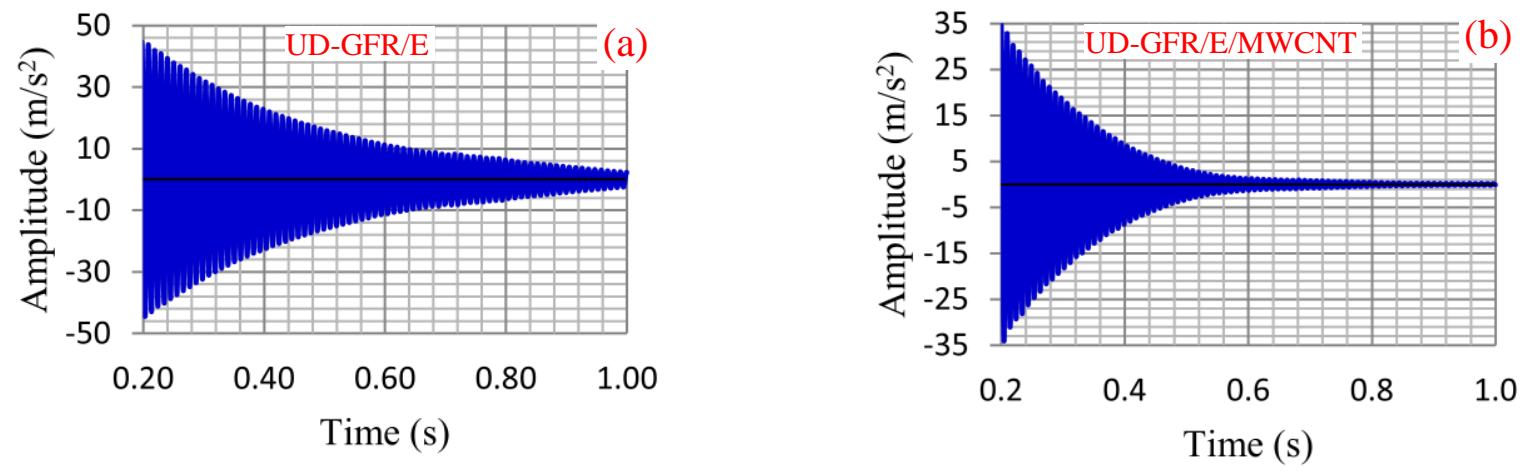

Fig. 9. Vibration amplitude vs. time history of (a) UD-GFR/E, and (b) UD/GFR/MWCNT/E.

The damping ratio of QI-GFR/MWCNT/E composite laminate is improved by $70.4 \%$ compared to QI-GFR/E composite laminate, Table 3 and Fig.10. This behavior can be clearly observed in the decay response of free vibration curves, which is pronounced for QIGFR/MWCNT/E laminate, Fig. 8b, compared to QI-GFR/E laminate, Fig. 8a. The improvement in the damping ratio is due to the reduction of the storage modulus and increase of loss modulus of QI-GFR/MWCNT/E laminate by $9.1 \%$ and $56.6 \%$ respectively, compared to QI-GFR/E laminate, Fig. 10. The increase in the damping ratio as a result of reduction in storage modulus was observed by Botelho et al. [58] and Talbot and Woodhouse [33].

The results in Table 3 and Fig.10 also show that the damping ratio of UD-GFR/MWCNT/E composite laminate is improved by about $100 \%$ compared to UD-GFR/E composites. This behavior can be clearly observed from the higher decay response of free vibration curve of UD-GFR/MWCNT/E laminate, Fig. 9b compared to UD-GFR/E laminate, Fig. 9a. This 
behavior is supported by the reduction of the storage modulus and increase of loss modulus of UD-GFR/MWCNT/E laminate by $5.2 \%$ and $37.5 \%$ respectively, compared to UD-GFR/E laminate, Fig. 10.

Table 3. Flexural dynamic moduli and damping properties of the investigated materials

\begin{tabular}{|c|c|c|c|c|c|c|c|c|c|}
\hline \multirow[b]{2}{*}{ Test materials } & \multirow{2}{*}{$\begin{array}{c}\text { Natural } \\
\text { frequency } \\
f_{n}(\mathrm{~Hz})\end{array}$} & \multicolumn{3}{|c|}{ Storage modulus } & \multirow[b]{2}{*}{$\tan \delta$} & \multirow{2}{*}{$\begin{array}{c}\text { Loss } \\
\text { modulus } \\
E^{\prime \prime} \\
(\mathrm{MPa})\end{array}$} & \multicolumn{3}{|c|}{ Damping ratio } \\
\hline & & $\begin{array}{c}E^{\prime} \\
(\mathrm{GPa})\end{array}$ & St. Dev. & $\begin{array}{l}\text { Gain/ } \\
\text { loss } \\
(\%)\end{array}$ & & & $\zeta(\%)$ & STDEV & $\begin{array}{c}\text { Gain/ } \\
\text { loss } \\
(\%) \\
\end{array}$ \\
\hline Neat epox & 35.62 & 2.247 & 0.0053 & & 0.043 & 96.933 & 2.157 & 0.101 & \\
\hline MWCNT/E & 36.20 & 2.410 & 0.00003 & 7.3 & 0.045 & 109.204 & 2.302 & 0.029 & 6.8 \\
\hline QI-GFR/E & 86.67 & 17.340 & 0.01929 & & 0.012 & 199.600 & 0.601 & 0.034 & \\
\hline QI-GFR/MWCNT/E & 94.45 & 15.769 & 0.01789 & -9.1 & 0.020 & 312.515 & 1.024 & 0.174 & 70.4 \\
\hline UD-GFR/E & 94.71 & 24.262 & 0.02936 & & 0.016 & 384.353 & 0.573 & 0.177 & \\
\hline UD-GFR/MWCNT/E & 103.0 & 23.003 & 0.00084 & -5.2 & 0.023 & 528.564 & 1.149 & 0.169 & 100.5 \\
\hline
\end{tabular}

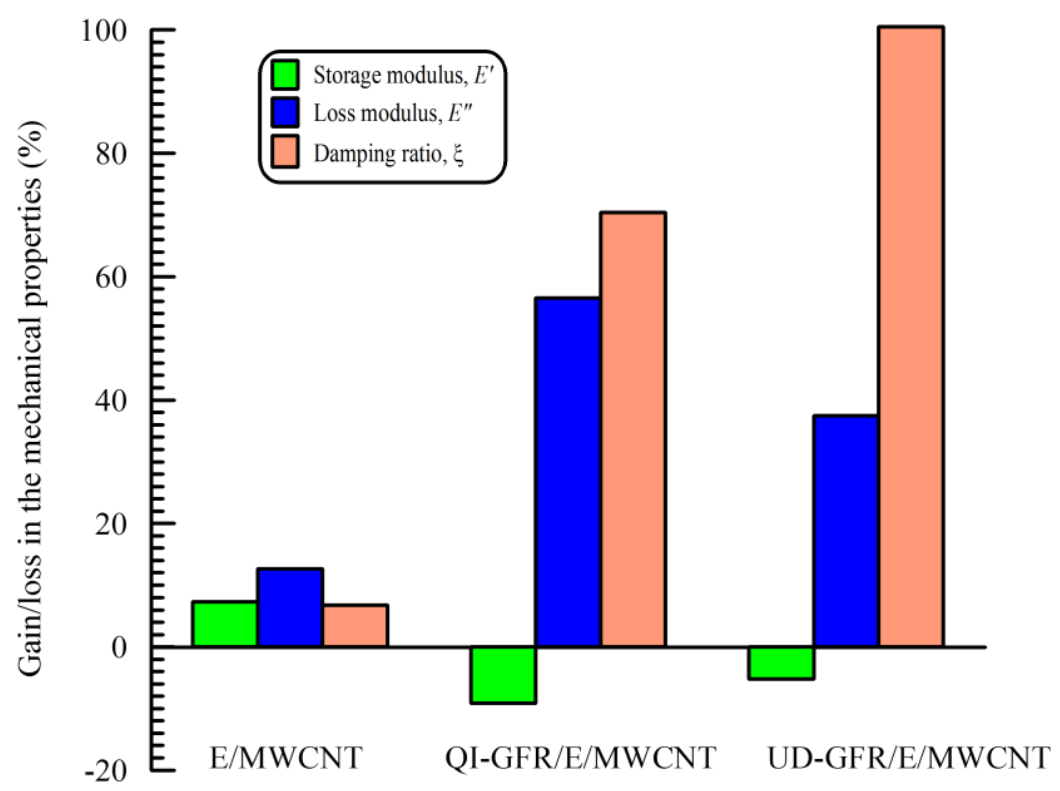

Fig. 10. Gain/loss in the mechanical properties of nanophased composite materials.

Although the damping ratio of neat epoxy (2.157) is more than three times higher than the damping ratio of QI-GFR/E (0.601) and UD-GFR/E (0.577) composite laminates, the improvement in the damping ratio owing to introducing $1 \mathrm{wt} \%$ MWCNT for the latter materials is about 12-14 times the improvement in the neat epoxy, Fig. 10. The high improvements in the damping ratio of hybrid multi-scale composites is due to the higher interfacial friction between microfibers, nanotubes, and epoxy of QI-GFR/MWCNT/E laminate than that dissipated due to the interfacial friction between nanotubes and epoxy in MWCNT/E nanocomposites. The large differences in the strain between the constituent materials of the hybridized composite laminates are another reason for enhancement the interfacial energy dissipation ability. 


\section{Conclusions}

Nanophased epoxy with $1 \mathrm{wt} \%$ MWCNT is ultrasonically prepared and used to fabricate MWCNT/E nanocomposite as well as to hybridize advanced composite laminates with different fiber configuration. The sonication conditions are carefully selected based on the extensive literature review. The hybrid multi-scale composite laminates is fabricated using hand lay-up technique. Applying rolling to the composite laminates using special aluminum roller contributes in removing any visible air bubbles, providing fast impregnation and good wetting of glass fibers with the nanophased epoxy and accordingly, improves the fiber/matrix interfacial bond strength. In additions, applying rolling with moderate pressure played an important role in de-agglomeration of the MWCNTs owing to their high aspect ratio that result in strong attractive forces between the MWCNTs themselves and the van der Waals attractive interactions. Accordingly, most of the investigated materials gain improvements in their mechanical properties. The storage modulus and damping ratio of MWCNT/E nanocomposite are improved by $7.3 \%$ and $6.8 \%$ respectively compared to the neat epoxy. The improvement in the damping ratio of MWCNT/E nanocomposites was due to the interfacial friction between the nanotubes and the polymer resin.

The storage moduli of the hybridized QI-GFR/MWCNT/E and UD-GFR/MWCNT/E composite laminates are reduced by $9.1 \%$ and $5.2 \%$ respectively compared to the composite without MWCNTs. The decay rate of free vibration curves is more pronounced for the tested materials that contains MWCNTs. In some cases, the improvement in damping ratio of the hybridized advanced composite materials is reached to $100 \%$. The high improvements in the damping ratio of hybridized composites are due to the higher interfacial friction between microfibers, nanotubes, and epoxy. The large differences in the strain between the constituent materials are another reason for enhancement the interfacial energy dissipation ability.

\section{References}

1. Tao K, Yang S, Grunlan JC, Kim Y-S, Dang B, Deng Y, Thomas RL, Wilson BL, Wei X. Effects of Carbon Nanotube Fillers on the Curing Processes of Epoxy Resin-Based Composites. J. Applied Polymer Science 102 (2006) 5248-5254.

2. Bittmann B, Haupert F, Schlarb AK, Ultrasonic dispersion of inorganic nanoparticles in epoxy resin, Ultrasonics Sonochemistry 16 (2009) 622-628

3. Chisholm N, Mahfuz H, Rangari VK, Ashfaq A, Jeelani S. Fabrication and mechanical characterization of carbon/SiC-epoxy nanocomposites. Composite Structures 67 (2005) $115-124$

4. Tee DI, Mariatti M, Azizan A., See CH, Chong KF, Effect of silane-based coupling agent on the properties of silver nanoparticles filled epoxy composites, Composites Science and Technology 67 (2007) 2584-2591

5. Chen C, Justice RS, Schaefer DW, Baur JW. Highly dispersed nanosilica-epoxy resins with enhanced mechanical properties. Polymer 49 (2008) 3805-3815

6. Sallam HEM, Khashaba UA, Seif MA, Abd-Elhamid M, Megahed AA, Megahed MA. Ultrasonic mixing of nanoparticles in epoxy resin. Int. Conf. on Nano-Technology for Green and Sustainable Construction 14-17 March, Cairo, Egypt (2010).

7. Uddin MF, Sun CT, Improved dispersion and mechanical properties of hybrid nanocomposites, Composites Science and Technology 70 (2010) 223-230.

8. Megahed MA, Megahed AA, Sallam HEM, Khashaba UA, Seif MA. Abd-Elhamid M. Nano-Reinforcement Effects on Tensile Properties of Epoxy Resin. MEATIP5, Fifth Int. Conf., Assiut University, Egypt, March 28-30, pp.123-135, (2011).

9. Zhou X, Shin E, Wang KW, Bakis CE. Interfacial damping characteristics of carbon nanotube-based composites. Composites Science and Technology 64 (2004) 2425-2437 
10. Lachman N. Wagner HD. Correlation between interfacial molecular structure and mechanics in CNT/epoxy nano-composites. Composites: Part A 41 (2010) 1093-1098

11. Bal S. Experimental study of mechanical and electrical properties of carbon nanofiber/epoxy composites. Materials and Design 31 (2010) 2406-2413

12. Ganguli S, Aglan H, Dennig P, Irvin G, Effect of Loading and Surface Modification of MWCNTs on the Fracture Behavior of Epoxy Nanocomposites, Journal of Reinforced Plastics and Composites, 25 (2006) 175-188.

13. Yang J-P, Chen Z-K, Feng Q-P, Deng Y-H, Li Y, Ni Q-Q, Yu S-Y. Cryogenic mechanical behaviors of carbon nanotube reinforced composites based on modified epoxy by poly(ethersulfone), Composites: Part B 43 (2012) 22-26.

14. Mujika F, Vargas G, Ibarretxe J, De Gracia J, Arrese A. Influence of the modification with MWCNT on the interlaminar fracture properties of long carbon fiber composites. Composites: Part B 43 (2012) 1336-1340

15. Srivastava VK, Modeling and mechanical performance of carbon nanotube/epoxy resin composites, Materials and Design, 39 (2012) 432-436.

16. Loos MR, Yang J, Feke DL, Manas-Zloczower I. Effect of block-copolymer dispersants on properties of carbon nanotube/epoxy systems. Composites Science and Technology 72 (2012) 482-488.

17. Hu N, Li Y, Nakamura T, Katsumata T, Koshikawa T, Arai m. Reinforcement effects of MWCNT and VGCF in bulk composites and interlayer of CFRP laminates. Composites: Part B 43 (2012) 3-9

18. Khan SU, Li CY, Siddiqui NA, Kim J-K. Vibration damping characteristics of carbon fiber-reinforced composites containing multi-walled carbon nanotubes. Composites Science and Technology 71 (2011) 1486-1494

19. Zhou Y, Pervin F, Jeelani S, Mallick PK. Improvement in mechanical properties of carbon fabric-epoxy composite using carbon nanofibers. J. Materials Processing Technology 198 (2008) 445-453.

20. Kim H-C, Kim S-K, Kim JT, Rhee K-Y, Kathi J. The Effect of Different Treatment Methods of Multiwalled Carbon Nanotubes on Thermal and Flexural Properties of Their Epoxy Nanocomposites. J. Polymer Science: Part B: Polymer Physics 48 (2010) 11751184.

21. Lin RM, Lub C. Modeling of interfacial friction damping of carbon nanotube-based nanocomposites. Mechanical Systems and Signal Processing 24 (2010) 2996-3012.

22. Zhou X, Shin E, Wang KW, Bakis CE. Interfacial damping characteristics of carbon nanotube-based composites. Composites Science and Technology 64 (2004) 2425-2437

23. Tanahashi M, Development of Fabrication Methods of Filler/Polymer Nanocomposites: With Focus on Simple Melt-Compounding-Based Approach without Surface Modification of Nanofillers, Materials 3(2010) 1593-1619.

24. Montazeri A, Montazeri N. Viscoelastic and mechanical properties of multi walled carbon nanotube/epoxy composites with different nanotube content. Materials and Design 32 (2011) 2301-2307.

25. Yang S, Lin W, Huang Y, Tien H, Wang J, Ma CM, Li S, Wang Y. Synergetic effects of graphene platelets and carbon nanotubes on the mechanical and thermal properties of epoxy composites, Carbon 49 (2011) 793-803.

26. Theodore M, Hosur M, Thomas J, Jeelani S., Influence of functionalization on properties of MWCNT-epoxy nanocomposites. Materials Science and Engineering A 528 (2011) 1192-1200.

27. Martone A, Formicola C, Giordano M, Zarrelli M. Reinforcement efficiency of multiwalled carbon nanotube/epoxy nano composites. Composites Science and Technology 70 (2010) 1154-1160. 
28. Jang J-S, Varischetti J, Lee G W, Suhr J, Experimental and analytical investigation of mechanical damping and $\mathrm{CTE}$ of both $\mathrm{SiO} 2$ particle and carbon nanofiber reinforced hybrid epoxy composites, Composites: Part A 42 (2011) 98-103

29. Martone A, Formicola C, Piscitelli F, Lavorgna M, Zarrelli M, Antonucci V, Giordano M. Thermo-mechanical characterization of epoxy nanocomposites with different carbon nanotube distributions obtained by solvent aided and direct mixing. J. eXPRESS Polymer Letters 6 (2012) 520-531

30. Tsai J-L, Wu M-D. Organoclay Effect on Mechanical Responses of Glass/Epoxy Nanocomposites. Compos Mater 6 (2008) 553-568

31. Sawi IE, Olivier PA, Demont P, Bougherara H. Investigation of the Effect of DoubleWalled Carbon Nanotubes on the Curing Reaction Kinetics and Shear Flow of an Epoxy Resin. Journal of Applied Polymer Science, 126 (2012) 358-366.

32. Pascault J-P, Williams RJJ. Epoxy polymers new materials and innovations, Wiley-VCH Verlag GmbH \& Co. KGaA; 2010.

33. Zhou T, Wang X, Wang T. Cure reaction of multi-walled carbon nanotubes/diglycidyl ether of bisphenol A/2-ethyl-4-methylimidazole (MWCNTs/DGEBA/EMI-2,4) nanocomposites: effect of carboxylic functionalization of MWCNTs. Polym Int 2009, 58, 445-452.

34. Talbot JP, Woodhouse J. The vibration damping of laminated plates. Composites Part A 28 (1997) 1007-1012.

35. Selmy A, El-Sonbaty I, Khashaba UA, Abdelkader A. Dynamic Viscoelastic Behavior of GFR/Vinylester and GFR/Epoxy Composites, Proc. of the $4^{\text {th }}$ Int. Eng. Conf., Mansoure University, Egypt, 1 (2004) 515-525.

36. Botelho EC, Campos AN, de Barros E, Pardini LC, Rezende MC. Damping behavior of continuous fiber/metal composite materials by the free vibration method. Composites: Part B 37 (2006) 255-263

37. KRV Kumar, Sundareswaran V. Mechanical and damping properties of epoxy cyanate matrix composite under varied temperatures. J. Engineering and Applied Sciences 5 (2010) 106-111

38. Ziaei-Rad S, Karimzadeh F, Kadkhodapour J, Jafari M. Energy Dissipation Capacity in MWCNTs Reinforced Metal Matrix Nanocomposites: An Overview of Experimental Procedure. In book: Advances in Nanocomposites - Synthesis, Characterization and Industrial Applications, Ch33, ISBN: 978-953-307-165-7, : InTech Publishers, Inc., (2011) 793-803.

39. Botelho EC, Rezende MC. Evaluation by Free Vibration Method of Moisture Absorption Effects in Polyamide/Carbon Fiber Laminates. Compos Mater 23 (2010) 207-225.

40. Montazeri A, Montazeri N. Viscoelastic and mechanical properties of multi walled carbon nanotube/epoxy composites with different nanotube content. Materials and Design 32 (2011) 2301-2307.

41. Venkatanarayanan PS, Stanley AJ. Intermediate velocity bullet impact response of laminated glass fiber reinforced hybrid (HEP) resin carbon nano composite. Aerospace Science and Technology 21 (2012) 75-83.

42. Mantena PR Al-Ostaz A, Cheng AHD. Dynamic response and simulations of nanoparticle-enhanced composites. Composites Science and Technology 69 (2009) 772779

43. Ayatollahi MR, Shadlou S, Shokrieh MM. Fracture toughness of epoxy/multi-walled carbon nanotube nano-composites under bending and shear loading conditions. Materials and Design 32 (2011) 2115-2124.

44. Sun L, Warren GL, O'Reilly JY, Everett WN, Lee SM, Davis D, Lagoudas D, Sue H-J. Mechanical properties of surface-functionalized SWCNT/epoxy composites. Carbon (2008) 320-328. 
45. Gibson RF, Ayorinde EO, Wen Y-F. Vibrations of carbon nanotubes and their composites: A review. Composites Science and Technology 67 (2007) 1-28

46. Qian D, Dickey C, Andrews R, Rantell T. Load transfer and deformation mechanism in carbon nanotube-polystyrene composites. Appl Phys Lett 2000;76(20):2868-70.

47. Velasco-Santos C, Martinez-Hernandez AL, Fisher F, Ruoff R, Castano VM. Dynamic mechanical and thermal analysis of carbon nanotube-methyl-ethyl-methacrylate nanocomposites. J Phys D2003;36:1423-8.

48. Taurozzi JS, Hackley VA, Wiesner MR. Protocol for the preparation of nanoparticle dispersions from powdered material using ultrasonic disruption. CEINT/NIST PROTOCOL (HTTP://CEINT.DUKE.EDU/ALLPROTOCOLS), Ver.1, 2010.

49. Preghenella M, Pegoretti A, Migliaresi C. Thermo-mechanical characterization of fumed silica-epoxy nanocomposites. Polymer 46 (2005) 12065-12072

50. Khashaba UA. On the Mechanical Behavior of $[0,+45,90,-45,0]$ Glass/Polyester Laminate. Proc. of $1^{\text {st }}$ Int. Conf. on Mech. Eng. Adv. Tech. for Indus. Prod., Assiut University, Egypt, Vol.1, PP.289-301, (1994).

51. Khasaba UA, Sebaey TA, Alnefaie KA. Failure and reliability analysis of pinned-joints composite laminates: Effects of stacking sequences. Composites: Part B, (2012), DOI: http://dx.doi.org/10.1016/j.compositesb.2012.09.066

52. Khashaba, U.A., Sallam, H.E.M., Al-Shorbagy, A.E., and Seif, M.A., "Effect of Washer Size and Tightening Torque on the Performance of Bolted Joints In Composite Structures", J. Composite Structures, Vol.73, pp.310-317, (2006).

53. Khashaba, U.A., Selmy, A.I., El-Sonbaty, I.A., and Megahed, M., "Behavior of notched and unnotched $[0 / \pm 30 / \pm 60 / 90]_{\mathrm{s}}$ GFR/Epoxy Composites under static and fatigue loads" J. Composite Structures, Vol.81, pp.606-613, (2007),

54. Khasaba UA, Sebaey TA, Alnefaie KA. Failure and reliability analysis of pinned-joints composite laminates: Effects of pin-hole clearance. J. Composite Materials, (2012) DOI: $10.1177 / 0021998312457196$.

55. Khasaba UA, Sebaey TA, Mahmoud FF, Selmy AI, Hamouda RM, Experimental and numerical analysis of pinned-joints composite laminates: Effects of stacking sequences. Accepted for publication, J. Composite Materials, (2012).

56. Chaudhuri RA, Balaraman K. A novel method for fabrication of fiber reinforced plastic laminated plates. Composite Structures 77 (2007) 160-170.

57. Botelho ес, Silva RA, Pardini LC, Rezende MC. A Review on the Development and Properties of Continuous Fiber/epoxy/aluminum Hybrid Composites for Aircraft Structures. Materials Research, 9 (2006) 247-256.

58. Botelho EC, Costa ML, Pardini LC, Rezende MC. Processing and hygrothermal effects on viscoelastic behavior of glass fiber/epoxy composites. J. Materials Science 40 (2005) $3615-3623$.

59. Botelho EC, Pardini LC, Rezende MC. Hygrothermal effects on damping behavior of metal/glass fiber/epoxy hybrid composites. Materials Science and Engineering A 399 (2005) 190-198.

60. Pilkey WD. Formulas for stress, strain, and structural matrices. $2^{\text {nd }}$ Ed. John Wiley \& Sons, Inc. (2005).

61. Buldum A, Lu JP. Atomic scale sliding and rolling of carbon nanotubes. Phys Rev Lett 1999;83:5050-3.

62. Falvo MR, Taylor II RM, Helser A, Chi V, Brooks Jr FP, Washburn S, Superfine R. Nanometre-scale rolling and sliding of carbon nanotubes. Nature 397 (1999) 236-237. 